\title{
Close interspecies interactions between prokaryotes from sulfureous environments
}

\author{
Johannes Müller ${ }^{\dagger}$ and Jörg Overmann ${ }^{\dagger *}$ \\ Bereich Mikrobiologie, Department Biologie I, Ludwig-Maximilians-Universität München, Planegg-Martinsried, Germany
}

Edited by:

Thomas E. Hanson, University of

Delaware, USA

Reviewed by:

Jennifer Macalady, Pennsylvania

State University, USA

James T. Hollibaugh, University of

Georgia, USA

*Correspondence:

Jörg Overmann, Leibniz-Institut,

Deutsche Samm/ung von

Mikroorganismen und Zellkulturen,

Inhoffenstraße 7B, 38124

Braunschweig, Germany.

e-mail: joerg.overmann@dsmz.de

${ }^{\dagger}$ Present address:

Johannes Müller and Jörg Overmann, Leibniz-Institut, Deutsche Sammlung von Mikroorganismen und

Zellkulturen Braunschweig and

Technical University of Braunschweig,

Inhoffenstraße 7B, 38124

Braunschweig, Germany.
Green sulfur bacteria are obligate photolithoautotrophs that require highly reducing conditions for growth and can utilize only a very limited number of carbon substrates. These bacteria thus inhabit a very narrow ecologic niche. However, several green sulfur bacteria have overcome the limits of immobility by entering into a symbiosis with motile Betaproteobacteria in a type of multicellular association termed phototrophic consortia. One of these consortia, "Chlorochromatium aggregatum," has recently been established as the first culturable model system to elucidate the molecular basis of this symbiotic interaction. It consists of 12-20 green sulfur bacteria epibionts surrounding a central, chemoheterotrophic betaproteobacterium in a highly ordered fashion. Recent genomic, transcriptomic, and proteomic studies of " $C$. aggregatum" and its epibiont provide insights into the molecular basis and the origin of the stable association between the two very distantly related bacteria. While numerous genes of central metabolic pathways are upregulated during the specific symbiosis and hence involved in the interaction, only a limited number of unique putative symbiosis genes have been detected in the epibiont. Green sulfur bacteria therefore are preadapted to a symbiotic lifestyle. The metabolic coupling between the bacterial partners appears to involve amino acids and highly specific ultrastructures at the contact sites between the cells. Similarly, the interaction in the equally well studied archaeal consortia consisting of Nanoarchaeum equitans and its host Ignicoccus hospitalis is based on the transfer of amino acids while lacking the highly specialized contact sites observed in phototrophic consortia.

Keywords: Chlorochromatium aggregatum, phototrophic consortia, symbiosis, green sulfur bacteria, Ignicoccus hospitalis, Nanoarchaeum equitans

\section{INTRODUCTION}

In their natural environment, planktonic bacteria reach total cell numbers of $10^{6} \mathrm{ml}^{-1}$, whereas in sediments and soils, $10^{9}$ and $10^{11}$ bacterial cells $\cdot \mathrm{cm}^{-3}$, respectively, have been observed (Fægri et al., 1977; Whitman et al., 1998). Assuming a homogenous distribution, distances between bacterial cells in these environments would amount to $112 \mu \mathrm{m}$ for planktonic, $10 \mu \mathrm{m}$ for sediment environments and about $1 \mu \mathrm{m}$ for soil bacteria (Overmann, 2001b). Taking into account the estimated number of bacterial species in soil that range from 500,000 (Dykhuizen, 1998) to $8.3 \times 10^{6}$ (Gans et al., 2005), the closest neighbors of each cell statistically should represent different species. A spatially close association of different bacterial species can result in metabolic complementation or other synergisms. In this context, the most extensively studied example is the conversion of cellulose to methane and carbon dioxide in anoxic habitats. The degradation is only possible by a close cooperation of at least four different groups of bacteria that encompass primary and secondary fermenting bacteria as well as two types of methanogens. Along this anaerobic food chain, end products of one group are exploited by the members downstream the flow of electrons. Although the bacteria involved in the first steps of cellulose degradation do not obligately depend on the accompanying bacteria for provision of growth substrates, they profit energetically from the rapid consumption of their excretion products. This renders their metabolism energetically more favorable or makes some reactions even possible (Bryant, 1979; Zehnder et al., 1982; McInerney, 1986; Schink, 1992). Recent studies of syntrophic communities in Lake Constance profundal sediments yielded new and unexpected results. The dominant sugar-degrading bacteria were not the typical fermenting bacteria that dominate in anaerobic sludge systems or the rumen environment. They rather represented syntrophic bacteria most closely related to the genus Bacillus that could only be grown anaerobically and in coculture with the hydrogen-using methanogen Methanospirillum hungatei (Müller et al., 2008). For efficient syntrophic substrate oxidation, close physical contact of the partner organisms is indispensable. Monocultures of Pelotomaculum thermopropionicum strain SI and Methanothermobacter thermautotrophicus show dispersed growth of the cells. In contrast, cocultures of the two strains formed tight aggregates when grown on propionate, for which the allowed distance for syntrophic propionate oxidation was estimated to be approximately $2 \mu \mathrm{m}$ (Ishii et al., 2005). Interestingly, the $\mathrm{H}_{2}$-consuming partner in syntrophic relationships can be replaced by an $\mathrm{H}_{2}$ purging culture vessel, allowing Syntrophothermus lipocalidus to grow on butyrate and Aminobacterium colombiense on alanine in 
pure culture (Adams et al., 2006). Thus, the syntrophic associations investigated to date are typically based on efficient $\mathrm{H}_{2}$-removal as obligate basis for their interdependence. Additional types of bacterial interactions have been described more recently. Cultures of Pseudomonas aeruginosa were shown to only grow on chitin if in coculture with a chitin degrading bacterium like Aeromonas hydrophila. In addition to simply growing on the degradation products produced by the exoenzymes of the partner, $P$. aeruginosa induced release of acetate in A. hydrophila by inhibiting its aconitase employing pyocyanin. The resulting incomplete oxidation of chitin to acetate by $A$. hydrophila is then exploited by $P$. aeruginosa for its own growth (Jagmann et al., 2010).

Although these well-characterized associations certainly are of major ecological relevance in their respective environments, they were typically obtained using standard defined growth media. As a result, presently available laboratory model systems were selected based on their ability to grow readily and - under at least some experimental conditions - on their own in pure culture. Obviously, this cultivation strategy counterselects against bacterial associations of obligately or at least tight interdependence. While the significant advances in the development of cultivation-independent techniques permit a partial analysis of so-far-uncultured associations (Orphan et al., 2001; Blumenberg et al., 2004; Pernthaler et al., 2008), laboratory grown model systems are still indispensable for in-depth studies of gene expression and metabolism. One model system of prokaryotic associations that meanwhile can be grown indefinitely in laboratory culture is the phototrophic consortium "Chlorochromatium aggregatum." This consortium represents the most highly developed bacteriabacteria symbiosis known to date. In parallel, the archaea-archaea association between Ignicoccus hospitalis and Nanoarchaeum equitans has emerged as a second laboratory model over the past years (Huber et al., 2003). A comparison between the two model systems that represent two different domains of life provides first insights into the general principles of tight interactions in the prokaryotic world.

\section{CHARACTERIZATION OF PHOTOTROPHIC CONSORTIA AND ESTABLISHING " CHLOROCHROMATIUM AGGREGATUM" AS A MODEL SYSTEM FOR CLOSE BACTERIAL INTERACTIONS}

Phototrophic consortia were already discovered in 1906 (Lauterborn, 1906) and invariably encompass green or brown-colored bacteria as epibionts that surround a central bacterium in a highly ordered fashion. Several decades later, electron microscopic analyses documented the presence of chlorosomes in the epibiont cells and led to the conclusion that the phototrophic epibionts belong to the green sulfur bacteria (Caldwell and Tiedje, 1975). This was confirmed by the application of fluorescence in situ hybridization employing a highly specific oligonucleotide probe against green sulfur bacterial 16S rRNA (Tuschak et al., 1999). The other partner bacterium of the symbiosis remained much less investigated than its epibionts. First, it had even been overlooked due to its low contrast in the light microscope. Over 90 years later, the central bacterium was identified as a Betaproteobacterium (Fröstl and Overmann, 2000) that exhibits a rod-shaped morphology with tapered ends (Overmann et al., 1998). Electron microscopy revealed the cells to be monopolarly monotrichously flagellated
(Glaeser and Overmann, 2003b). Within the Betaproteobacteria the central bacterium represents a so far isolated phylogenetic lineage belonging to the family of the Comamonadaceae. The closest relatives are Rhodoferax spp., Polaromonas vacuolata and Variovorax paradoxus (Kanzler et al., 2005).

Based solely on their morphology, 10 different phototrophic consortia can be distinguished to date (Overmann, 2001a; Overmann and Schubert, 2002). The majority of the morphotypes are motile, motility being conferred by the central colorless bacterium. The 13-69 epibiont cells are either green or brown-colored representatives of the green sulfur bacteria. The smaller consortia like "Chlorochromatium aggregatum" (harboring green epibionts) and "Pelochromatium roseum" (brown epibionts), are barrel shaped and consist of 12-20 epibiont cells (Overmann et al., 1998). Rather globular in shape and consisting of $\geq 40$ epibionts are the significantly larger consortia "Chlorochromatium magnum" (green epibionts; Fröstl and Overmann, 2000), "Pelochromatium latum" (brown epibionts; Glaeser and Overmann, 2004) and "Pelochromatium roseo-viride” (Gorlenko and Kusnezow, 1972). The latter consortium is the only one harboring two types of epibionts, with brown cells forming an inner layer and green ones an outer layer. "Chloroplana vacuolata" and "Cylindrogloea bactifera" can be distinguished from the other consortia by their immotility and different cell arrangement. "Chloroplana vacuolata" consists of rows of green sulfur bacteria alternating with colorless bacteria forming a flat sheath (Dubinina and Kuznetsov, 1976), with both species containing gas vacuoles. In "Cylindrogloea bactifera," a slime layer containing green sulfur bacteria is surrounding filamentous, colorless bacteria (Perfiliev, 1914; Skuja, 1956). Since they consist of two different types of bacteria, the names of consortia are without standing in nomenclature (Trüper and Pfennig, 1971) and, accordingly, are given here in quotation marks.

When 16S rRNA gene sequences of green sulfur bacteria from phototrophic consortia were investigated from a total of 14 different lakes in Europe and North America (Glaeser and Overmann, 2004), a total of 19 different types of epibionts could be detected. Of those, only two types occurred on both, the European and North American continents. Although morphologically identical consortia from one lake always contained just a single epibiont phylotype, morphologically indistinguishable consortia from different lakes frequently harbored phylogenetically different epibionts. Phylogenetic analyses demonstrated that the epibiont sequences do not constitute a monophyletic group within the radiation of green sulfur bacteria. Therefore, it was concluded that the ability to form symbiotic interactions was gained independently by different ancestors of epibionts or, alternatively, was present in the common ancestor of the green sulfur bacteria. In parallel, the phylogeny of central bacteria of phototrophic consortia was investigated. This analysis exploited a rare tandem $r r n$ operon arrangement in these bacteria that involves an unusual short interoperon spacer of 195 bp (Pfannes et al., 2007). Betaproteobacteria with this genomic feature were exclusively encountered in chemocline environments and form a novel, distinct and highly diverse subcluster within the subphylum. Within this cluster, the sequences of central bacteria of phototrophic consortia were found to be polyphyletic. Thus, like in their green sulfur bacterial counterparts, the ability to become a central bacterium may have evolved independently in 
several lineages of betaproteobacteria, or was already present in a common ancestor of the different central bacteria. In the barrelshaped types of consortia, the green sulfur bacterial epibionts have overcome their immotility. However, the existence of two different types of non-motile consortia indicates that motility is not the only advantage gained by green sulfur bacteria that form these interspecies association with heterotrophic bacteria. As described below (see Evidence for Metabolic Coupling), the exchange of metabolites seems to play a major role in the symbiotic interaction, and might therefore be the key selective factor of symbiosis in immotile phototrophic consortia.

At present, "Chlorochromatium aggregatum" is the only phototrophic consortium that can be successfully cultivated in the laboratory (Fröstl and Overmann, 1998). From the stable enrichment culture it was possible to isolate the epibiont of the consortium in pure culture using deep agar dilution series supplemented with optimized growth media (Vogl et al., 2006). On the basis of $16 \mathrm{~S}$ rRNA sequence comparisons, the strain is distantly related to other known green sulfur bacteria ( $\leq 94.6 \%$ sequence homology) and therefore represents a novel species within the genus Chlorobium, Chlorobium chlorochromatii strain CaD. However, physiological and molecular analyses of the novel isolate did not reveal any major differences to already described strains of the phylum Chlorobi. Thus, C. chlorochromatii $\mathrm{CaD}$ is obligately anaerobic and photolithoautotrophic, and photoassimilates acetate and peptone in the presence of sulfide and hydrogen carbonate (Vogl et al., 2006). As a difference to its free-living counterparts the epibiont contains only a low cellular concentration of carotenoids and cannot synthesize chlorobactene. A similar anomaly had also been observed in the brown epibionts of the phototrophic consortium "Pelochromatium roseum" that do not seem to form isorenieratene (Glaeser et al., 2002; Glaeser and Overmann, 2003a). In contrast to the epibiont of "Chlorochromatium aggregatum," all efforts to cultivate the central bacterium in the absence of its epibionts have failed so far.

\section{PREADAPTATION OF GREEN SULFUR BACTERIA TO SYMBIOSIS}

Green sulfur bacteria (Family Chlorobiaceae) constitute a phylogenetically distinct lineage within the phylum Chlorobi of the domain Bacteria (Overmann, 2001a). Recently, the chemotrophic Ignavibacterium album gen. nov. sp. nov., was described (Iino et al., 2010), this novel isolate represents a deeply branching phylogenetic lineage and hence a new class within the phylum Chlorobi, whereas all green sulfur bacteria sensu stricto that are known to date represent strictly anaerobic photolithoautotrophs. Since a considerable number of different $16 \mathrm{~S}$ rRNA gene sequence types of green sulfur bacteria engaged in a symbiotic association with the central Betaproteobacteria (see section Characterization of Phototrophic Consortia and Establishing "Chlorochromatium aggregatum" as a Model System for Close Bacterial Interactions), green sulfur bacteria may be specifically preadapted to symbiosis and the advent of symbiotic green sulfur bacterial epibionts during evolution may have involved only limited genomic changes. Indeed, several of the physiological characteristics of green sulfur bacteria are regarded as preadaptive traits for interactions with other prokaryotes.
One feature of green sulfur bacteria which provides interaction with other prokaryotes is their carbon metabolism. Green sulfur bacteria autotrophically assimilate $\mathrm{CO}_{2}$ through the reductive tricarboxylic acid cycle. One instantaneous product of photosynthetic fixation of $\mathrm{CO}_{2}$ is 2-oxoglutarate, and 2-oxo acids represent typical excretion products of photosynthesizing cells (Sirevag and Ormerod, 1970). In natural environments, Chlorobium limicola excretes photosynthetically fixed carbon (Czeczuga and Gradzki, 1973) and thus constitutes a potential electron donor for associated bacteria. Excretion of organic carbon compounds has also been demonstrated for C. chlorochromatii strain $\mathrm{CaD}$, the epibiont of the phototrophic consortium "Chlorochromatium aggregatum" (Pfannes, 2007). Vice versa, green sulfur bacteria can also take advantage of organic carbon compounds produced by other, for example, fermenting, bacteria. During phototrophic growth, they are capable of assimilating pyruvate as well as acetate and propionate through reductive carboxylation in the presence of $\mathrm{CO}_{2}$ (pyruvate:ferredoxin oxidoreductase; Uyeda and Rabinowitz, 1971) or $\mathrm{HCO}_{3}^{-}-$(phosphoenolpyruvate carboxylase; Chollet et al., 1996). The assimilation of organic carbon compounds reduces the amount of electrons required per unit cellular carbon synthesized. This capability thus enhances photosynthetic growth yield and results in a competitive advantage for green sulfur bacteria.

In their natural environment, green sulfur bacteria are limited to habitats where light reaches anoxic bottom waters such as in thermally stratified or meromictic lakes. Here, cells encounter conditions favorable for growth exclusively in a rather narrow (typically $\mathrm{cm}$ to $\mathrm{dm}$ thick) zone of overlap between light and sulfide. Compared to other phototrophs, green sulfur bacteria are extremely low-light adapted and capable of exploiting minute light quantum fluxes by their extraordinarily large photosynthetic antenna complexes, the chlorosomes. In contrast to other photosynthetic antenna complexes, the bacteriochlorophyll $c, d$, or $e$ molecules in chlorosomes are not attached to a protein scaffold but rather form paracrystalline, tight aggregates (Griebenow and Holzwarth, 1989; Blankenship et al., 1995). Until recently, the heterogeneity of pigments complicated the identification of the structural composition of chlorosomes. When a Chlorobaculum tepidum triple mutant that almost exclusively harbors BChl $d$ was constructed, a syn-anti stacking of monomers and self-assembly of bacteriochlorophylls into tubular elements could be demonstrated within the chlorosomes (Ganapathy et al., 2009).

Since they minimize the energetically costly protein synthesis, chlorosomes represent the most effective light harvesting system known. Up to 215,000 \pm 80,000 bacteriochlorophyll molecules (in Chlorobaculum tepidum; Montano et al., 2003) can constitute a single chlorosome, that is anchored to 5-10 reaction centers in the cytoplasmic membrane (Amesz, 1991). This ratio of chlorophyll to reaction center is orders of magnitudes higher compared with other photosynthetic antenna structures. In the phycobilisomes of cyanobacteria the ratio is 220:1 (Clement-Metral et al., 1985), 100-140:1 in light harvesting complex II of anoxygenic phototrophic proteobacteria (Van Grondelle et al., 1983) and 28:1 in the light harvesting complex I (Melkozernov et al., 2006). The 
enormous size of the photosynthetic antenna of green sulfur bacteria enables them to colonize extreme low-light habitats up to depths of $100 \mathrm{~m}$ in the Black Sea (Overmann et al., 1992; Marschall et al., 2010) or below layers of other phototrophic organisms like purple sulfur bacteria (Pfennig, 1978). Commensurate with their adaptation to extreme light limitation, green sulfur bacteria also exhibit a significantly reduced maintenance energy requirement compared to other bacteria (Veldhuis and van Gemerden, 1986; Overmann et al., 1992). Chlorobium phylotype BS-1 isolated from the Black Sea maintained a constant level of cellular ATP over 52 days, if exposed to low-light intensities of $0.01 \mathrm{mmol}$ quanta $\mathrm{m}^{-2} \mathrm{~s}^{-1}$ (Marschall et al., 2010). The high efficiency of green sulfur bacteria allows them to colonize habitats in which other photosynthetic bacteria are unable to grow. A chemotrophic bacterium that associates with green sulfur bacteria and is capable of exploiting part of their fixed carbon thus would gain a selective advantage during evolution.

\section{SELECTIVE ADVANTAGE OF CONSORTIA FORMATION}

Free-living representatives of green sulfur bacteria are immotile and only species able to produce gas vacuoles can regulate their vertical position. However, changes in buoyant density mediated by gas vesicle production occur only over time periods of several days (Overmann et al., 1991). Due to the motility that is conferred by the flagellated central bacterium, the consortium can orientate itself much faster in light and sulfide gradients and reaches locations with optimal conditions for photosynthesis in a shorter period of time. In fact, "C. aggregatum" has been found to vary its position rapidly across the chemocline in two Tasmanian lakes (Croome and Tyler, 1984). A scotophobic response, that is swimming away from darkness toward light, has been demonstrated for intact consortia in the laboratory (Fröstl and Overmann, 1998; Glaeser and Overmann, 2003a) and leads to a rapid accumulation of consortia in (dim)light. In addition, laboratory cultures as well as natural populations of phototrophic consortia exhibit a strong chemotaxis toward sulfide (Fröstl and Overmann, 1998; Glaeser and Overmann, 2003b).

In contrast to light, the spatial distribution of sulfide does not necessarily occur in a strictly vertical gradient in the natural habitat. In analogy to the presence of point sources of organic carbon substrates (Azam and Malfatti, 2007) that attract chemotrophic aquatic bacteria in zones extending tens to hundred micrometer around the sources (Krembs et al., 1998), organic particles sinking into anoxic water layers may develop into hot spots of sulfate reduction. Due to the motility of phototrophic consortia, the otherwise immotile green sulfur bacteria epibionts would gain rapid access and thus a highly competitive advantage over their free-living relatives especially in laterally inhomogeneous environments. If photosynthetically fixed carbon is indeed transferred to the central bacterium, however, the net balance of the increased availability of sulfide and the loss of electrons to the central bacterial partner must still be positive for the green sulfur bacterium.

The tight packing of epibiont cells in the phototrophic consortium raises the question whether dissolved compounds can actually diffuse into the consortium and reach the central bacterium or if the epibionts represent a diffusion barrier around the central bacterium. This question was addressed by adding carboxyfluorescein diacetate succinimidyl ester (CFDA-SE) to intact consortia and following fluorescence in epibionts and central bacteria over time (Bayer, 2007). CFDA-SE enters cells by diffusion and, after cleavage by intracellular esterase enzymes, confers fluorescence to the bacterial cell. Central bacteria were already detectable after $2 \mathrm{~min}$ of exposure (Figure 1A), whereas epibionts in the same sample could only be detected after $12 \mathrm{~min}$ of incubation with CFDA-SE and developed only weak fluorescence (Figure 2). The fluorescence activity of the central rod remained strong throughout the experiment which is indicative of a higher esterase activity than in the epibiont. Since the central bacterium is presumably heterotrophic, it is likely to express esterases such as lipases at a higher number or intracellular concentration. These results indicate that, even in intact phototrophic consortia, diffusion of small water-soluble molecules toward the central bacterium is not significantly impeded by the surrounding layer of epibionts. Therefore, sensing of sulfide by the central bacterium itself, eliciting the sulfide chemotactic response observed for the consortia is feasible. However, in analogy to the proposal that heterotrophic bacteria colonizing the heterocysts of cyanobacteria may shield them from high ambient $\mathrm{O}_{2}$ concentrations (Paerl and Kellar, 1978), one could speculate that the consumption of sulfide by the epibionts might decrease the concentration of sulfide reaching the central bacterium. Thus, if sensing of sulfide is carried out by the central bacterium, the photosynthetic activity of the epibiont could have a regulatory function regarding the chemotaxis of the consortium toward sulfide.

The orientation of the consortium toward light and sulfide is of special interest since probably neither of these attractants is used in the metabolism of the motile central
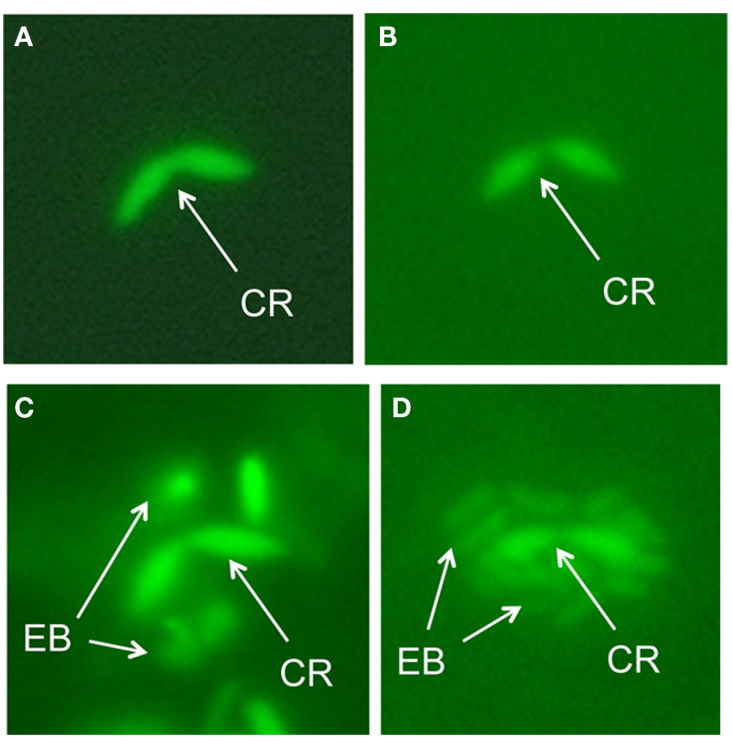

FIGURE 1 | CFDA-SE stained phototrophic consortia. CR, central rod; $\mathrm{EB}$, epibiont. (A,B) 2 (A) and $5 \mathrm{~min}(\mathbf{B})$ of staining; only the central bacterium is visible. (C) 12 min of staining; epibionts become visible. (D) 15-min staining; whole consortium stained. 


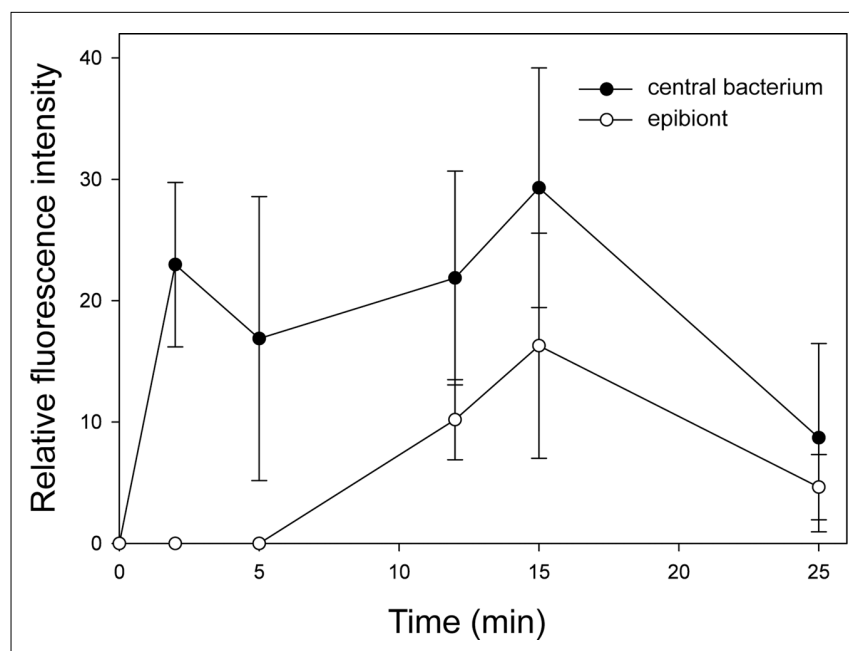

FIGURE 2 | Time course of fluorescence intensities of CFDA-SE stained central bacteria and epibiont cells.

bacterium. From the perspective of the epibiont, relying on a non-photosynthetic partner for transportation would pose the risk of being carried into dark, and/or sulfide-free unfavorable deeper water layers. Consortia formation thus would either require the expression of a suitable chemotactic response (i.e., toward sulfide) and of a suitable photosensor in the central bacterium or effective means of interspecific communication. Acquisition of these traits must have been a critical stage and happened early during the coevolution of the bacterial partners in phototrophic consortia.

In recent ultrastructural studies of the central bacterium of "C. aggregatum," conspicuous 35 -nm-thick and up to $1-\mu \mathrm{m}$-long zipper-like crystalline structures were found that resemble the chemotaxis receptor Tsr of Escherichia coli (Wanner et al., 2008). In a comparative ultrastructural study of 13 distantly related organisms harboring chemoreceptor arrays from all seven major signaling domain classes, receptors were found to possess an universal structure which has presumably been conserved over long evolutionary distances (Briegel et al., 2009). The prominent ultrastructure discovered in the central bacterium exhibits several similarities to the chemoreceptors reported and provides a first indication that a chemotaxis receptor is present in the central bacterium.

One characteristic feature of green sulfur bacteria that provides a basis for interaction with other bacteria is the extracellular deposition of sulfur globules (zero valence sulfur), the initial product of sulfide oxidation during anoxygenic photosynthesis. This sulfur is further oxidized to sulfate only after depletion of sulfide. The extracellular deposition renders the sulfur available to other bacteria such as, for example, sulfur reducers. Therefore, it had initially been proposed that the central bacterium of phototrophic consortia is a sulfate- or sulfur-reducing bacterium. In that case, extracellular sulfur produced by the green sulfur bacteria could be utilized by the central bacterium to establish a close sulfur cycle within the phototrophic consortium (Pfennig, 1980). Such a sulfur cycle has been established in defined syntrophic cocultures of Chlorobium phaeovibrioides and Desulfuromonas acetoxidans. In these cocultures, acetate is oxidized by Desulfuromonas acetoxidans with sulfur as electron acceptor, which leads to a recycling of the sulfide that can then be used again for anoxygenic photosynthesis by Chl. phaeovibrioides. Only minute amounts of sulfide $(10 \mu \mathrm{M})$ are required to keep this sulfur cycle running (Warthmann et al., 1992). Similarly, sulfate reducers are able to grow syntrophically with green sulfur bacteria with only low equilibrium concentrations of sulfide (Biebl and Pfennig, 1978). In addition, such interactions may also encompass transfer of organic carbon compounds between the partners. In mixed cultures of Desulfovibrio desulfuricans or D. gigas with Chlorobium limicola strain 9330, ethanol is oxidized to acetate with sulfate as electron acceptor and the acetate formed is incorporated by Chl. limicola such that ethanol is completely converted to cell material.

However, the hypothesis of a sulfur cycling within phototrophic consortia became less likely by the discovery that the central bacterium belongs to the Betaproteobacteria, whereas only the Deltaproteobacteria or Firmicutes encompass typical sulfur- or sulfate-reducers (Fröstl and Overmann, 2000). As shown above, the exchange of sulfur compounds has been established across a physiologically and phylogenetically diverse range of prokaryotes. But those symbiotic interactions were not accompanied by consortia formation. It is thereby concluded, that sulfur cycling does not appear to be sufficiently selective to explain the advent of phototrophic consortia during evolution.

\section{MOLECULAR BASIS OF THE SYMBIOTIC INTERACTION IN PHOTOTROPHIC CONSORTIA FEATURES OF THE EPIBIONT GENOME THAT RELATE TO SYMBIOSIS}

In order to make a first assessment of the imprint of symbiotic lifestyle on the genome of the epibiont, the genome features of $C$. chlorochromatii $\mathrm{CaD}$ can be compared to those of Nanoarchaeum equitans and Ignicoccus hospitalis in the archaeal consortia.

Nanoarchaeum equitans is the representative of a new archaeal phylum Nanoarchaeota and most likely represents a parasitic epibiont of Ignicoccus. The N. equitans genome comprises only $491 \mathrm{~kb}$ and encodes 552 genes, rendering it the smallest genome for an exosymbiont known to date (Waters et al., 2003). Genome reduction includes almost all genes required for the de novo biosynthesis of amino acids, nucleotides, cofactors, and lipids as well as many known pathways for carbon assimilation. Commensurate with this findings, the Nanoarchaeum equitans epibiont appears to acquire its lipids from its host (Waters et al., 2003). Yet, the $N$. equitans genome harbors only few pseudogenes or regions of non-coding DNA compared with genomes of obligate bacterial symbionts that undergo reductive evolution, and thus is genomically significantly more stable than other obligate parasites. This has been interpreted as evidence for a very ancient relationship between N. equitans and Ignicoccus (Brochier et al., 2005). The recent bioinformatic analysis also suggest that $N$. equitans represents a derived, fast-evolving euryarchaeal lineage rather than the representative of a deep-branching basal phylum (Brochier et al., 2005). With a size of $1.30 \mathrm{Mbp}$ and 1494 predicted open reading frames (ORFs), the genome of I. hospitalis shows a pronounced 
genome reduction that has been attributed to the reduced metabolic complexity of its anaerobic and autotrophic lifestyle and an highly efficient adaptation to the low energy yield of its metabolism (Podar et al., 2008).

Similar to $I$. hospitalis, the genome size of Pelagibacter ubique (1.31 Mbp and $1354 \mathrm{ORFs}$ ) so far marks the lower limit of freeliving organisms. It exhibits hallmarks of genome streamlining such as the lack of pseudogenes, introns, transposons, extrachromosomal elements, only few paralogs, and the shortest intergenic spacers yet observed for any cell (Giovannoni et al., 2005). This likely reduces the costs of cellular replication (Mira et al., 2001). As a second feature, the genome of $P$. ubique has a $\mathrm{G}: \mathrm{C}$ content of $29.7 \%$ that may decrease its cellular requirements for fixed nitrogen (Dufresne et al., 2005).

By comparison, a much larger genome size of $2.57 \mathrm{Mbp}$ has been determined for $C$. chlorochromatii $\mathrm{CaD}$. This size represents the average value of the 11 other publicly available genomes of green sulfur bacteria (Table 1). Thus, a reduction in genome size that is characteristic for bacterial endosymbionts (Andersson and Kurland, 1998; Moran et al., 2002, 2008) and for the archaeal consortium (Podar et al., 2008) did not occur during the evolution of the epibiont of " $C$. aggregatum." This suggests (i) a shorter period of coevolution of the two partner bacteria in phototrophic consortia, (ii) a significantly slower rate of evolution of their genomes, or (iii) that the genome of C. chlorochromatii is not undergoing a streamlining process as observed in other symbiotic associations. The latter suggestion would indicate a lack of selective advantage for "Chl. aggregatum" from genome streamlining.

Wet-lab and in silico analyses of the epibiont genome revealed the presence of several putative symbiosis genes. An initial combination of suppression subtractive hybridization with bioinformatics approaches identified four ORFs as candidates. Two of the ORFs (Cag0614 and 0616) exhibit similarities to putative filamentous hemagglutinins that harbor RGD (arginine-glycineaspartate) tripeptides. In pathogenic bacteria, hemagglutinins with these motifs are involved in the attachment to mammalian cells (Vogl et al., 2008). Most notably, a comparative study of 580 sequenced prokaryotic genomes revealed that Cag 0614 and 0616 represent the largest genes detected in prokaryotes so far. In fact, Cag 0616 is only surpassed in length by the exons of the human titin gene (Reva and Tümmler, 2008). The two other genes detected (Cag1919 and 1920) resembles repeats in toxin (RTX)-like proteins and hemolysins, respectively. All four genes have in common that they are unique in C. chlorochromatii $\mathrm{CaD}$ and that certain domains of their inferred products are only known from bacterial virulence factors. If the four genes were not misassigned, they are potentially involved in the symbiotic interaction between the two partner bacteria in phototrophic consortia.

To identify additional symbiosis genes, in silico subtractive hybridization between the genome sequence of $C$. chlorochromatii $\mathrm{CaD}$ and the other 11 sequences of green sulfur bacterial genomes was performed. This yielded 186 ORFs unique to the epibiont (Wenter et al., 2010), 99 of which encode for hypothetical proteins of yet unknown function. Although this provides a large number of putative symbiosis genes, the numbers are rather low compared to the unique and unknown ORFs in the other green sulfur bacteria (Table 1). Even if it is assumed that all of these unknown genes encode for proteins involved in symbiosis, this number is still rather small compared to the 1387 genes encoding niche-specific functions in enterohemorrhagic E. coli O157:H7 (Perna et al., 2001). Low numbers of niche-specific genes have been reported for Salmonella enterica or Bacillus anthracis and have been interpreted as indication for preadaptation of the non-pathogenic ancestor. This supports the hypothesis of a preadaptation of green sulfur bacteria to symbiosis. From a broader perspective, the discovery of putative symbiosis genes in the epibiont genome that resemble typical bacterial virulence factors suggest that modules thought to be limited to bacterial pathogens are employed in a much wider biological context.

\section{THE REGULATORY RESPONSE EVOKED BY SYMBIOSIS INVOLVES GENES OF THE NITROGEN METABOLISM}

When the proteome of $C$. chlorochromatii $\mathrm{CaD}$ in the freeliving state was compared to that of the symbiotic state by $2-\mathrm{D}$ differential gel electrophoresis (2-D DIGE), it became apparent that symbiosis-specific regulation involves genes of central metabolic pathways rather than symbiosis-specific genes (Wenter et al., 2010). In the soluble proteome, 54 proteins were expressed exclusively in consortia. Among them were a considerable number of proteins involved in amino acid metabolism. These included glutamate synthase, 2-isopropylmalate synthase, and the nitrogen regulatory protein P-II. The latter showed the highest overall upregulation that amounted to a 189-fold increase in transcript abundance as determined by subsequent RT-qPCR. It is thereby concluded that the amino acid requirement in the consortium is higher than in the epibiont in pure culture.

Parallel investigations of the membrane proteome revealed that a branched chain amino acid $\mathrm{ABC}$-transporter binding protein was expressed only in the associated state of the epibiont. Interestingly, the expression of the ABC-transporter binding protein could also be induced in the free-living state by addition of sterile filtered supernatant of the consortia culture, but not with peptone or branched chain amino acids themselves. This is an evidence for a signal exchange between the two symbiotic partners mediated through the surrounding medium.

The results of the proteome analysis were supplemented by transcriptomic studies of the epibiont in the associated and the free-living state (Wenter et al., 2010). Of the 328 differentially expressed genes, 19 genes were found to be up-regulated and are involved in amino acid synthesis while six genes of the amino acid pathways were down-regulated. The conclusion that nitrogen metabolism of the epibiont is stimulated in the symbiotic state is commensurate with the simultaneous up-regulation of the nifH, nifE, and nifB genes and with the prominent expression of the P-II nitrogen regulatory protein.

The results of the proteome analyses indicates that (i) a signal exchange occurs between the central bacterium and the epibiont that controls the expression of symbiosis relevant genes and (ii) 
Table 1 | Comparison of green sulfur bacterial genomes against each other.

\begin{tabular}{|c|c|c|c|c|c|c|}
\hline Green sulfur bacterium & $\begin{array}{l}\text { Genome } \\
\text { size (Mbp) }\end{array}$ & $\begin{array}{l}\text { ORFs-in } \\
\text { genome }\end{array}$ & $\begin{array}{l}\text { Unique } \\
\text { ORFs }\end{array}$ & $\begin{array}{l}\text { Genome } \\
(\%)\end{array}$ & $\begin{array}{l}\text { Unknown } \\
\text { unique ORFs }\end{array}$ & $\begin{array}{l}\mathbf{G}+\mathbf{C} \\
(\%)\end{array}$ \\
\hline Chlorobium chlorochromatii CaD3 & 2.57 & 2002 & 186 & 9.3 & 99 & 44.3 \\
\hline Chlorobaculum tepidum TLS & 2.15 & 2252 & 396 & 17.6 & 366 & 56.5 \\
\hline Chlorobium ferrooxidans DSM 13031 & 2.54 & 2158 & 181 & 8.4 & 84 & 50.1 \\
\hline Chlorobium limicola DSM 245 & 2.76 & 2522 & 204 & 8.1 & 149 & 51.3 \\
\hline Chlorobium phaeobacteroides DSM 266 & 3.13 & 2743 & 266 & 9.7 & 164 & 48.4 \\
\hline Chlorobium phaeovibrioides DSM 265 & 1.97 & 1773 & 56 & 3.2 & 33 & 53.0 \\
\hline Chloroherpeton thalassium ATCC 35110 & 3.29 & 2731 & 971 & 35.6 & 396 & 45.0 \\
\hline Pelodictyon phaeoclathratiforme BU-1 & 3.02 & 2911 & 550 & 18.9 & 394 & 48.1 \\
\hline Chlorobium luteolum DSM 273 & 2.36 & 2083 & 100 & 4.8 & 49 & 57.3 \\
\hline
\end{tabular}

In silico subtractive hybridization was conducted with the Phylogenetic Profiler available at the DOE Joint genome Institute website (http://img.jgi.doe.gov).

metabolic coupling between C. chlorochromatii and the central Betaproteobacterium may involve amino acids. Metabolic coupling has also been detected in the two-membered microbial consortium consisting of Anabaena sp. strain SSM-00 and Rhizobium sp. strain WH2K. Between the two species, nanoscale secondary ion mass spectrometry (nanoSIMS) analyses indicated an exchange of metabolites containing ${ }^{13} \mathrm{C}$ and ${ }^{15} \mathrm{~N}$ fixed by the heterocysts of the filamentous cyanobacteria to the attached epibiont cells (Behrens et al., 2008).

\section{EVIDENCE FOR METABOLIC COUPLING}

The proteomic and transcriptomic evidence described in the preceding paragraphs point toward an exchange of metabolites between the two symbiotic partners of " $C$. aggregatum." Meanwhile, more direct evidence for a transfer of carbon between the bacterial partners of phototrophic consortia has been obtained. In a series of labeling experiments with ${ }^{14} \mathrm{C}$, a rapid exchange of labeled carbon from the epibiont to the central bacterium was observed (Johannes Müller and Jörg Overmann, unpublished observations). External addition of several amino acids as well as 2-oxoglutarate to the growth medium inhibited this carbon exchange. Together with the observed excretion of photosynthetically fixed carbon by $C$. chlorochromatii $\mathrm{CaD}$, these results suggest a transfer of newly synthesized small molecular weight organic matter to the central bacterium. Such a transfer may provide the central bacterium with a selective advantage in illuminated sulfidic environments where degradation of organic matter proceeds mainly through the anaerobic food chain and involves competition of chemoheterotrophs for organic carbon compounds. By transferring amino acids, the epibiont may not only support growth of the central bacterium with respect to carbon, but also to nitrogen and even sulfur.

To date it has remained unclear whether the association in phototrophic consortia also offers an additional advantage for the green sulfur bacterial epibiont apart from the gain of motility and the resulting potential increase in sulfide supply. Extensive substrate utilization assays with C. chlorochromatii $\mathrm{CaD}$ revealed that only the addition of acetate and peptone stimulated the growth of the epibiont of "C. aggregatum" (Vogl et al., 2006). It remains to be tested whether transfer of organic carbon in this form occurs in the opposite direction from the central bacterium to the epibiont.

Stable isotope signatures $\left({ }^{13} \mathrm{C}\right)$ of $I$. hospitalis and N. equitans were analyzed to investigate a possible carbon transfer between the two archaeal partners. Labeling patterns of Ignicoccus amino acids grown in the coculture as well as in pure culture were compared to those in the Nanoarchaeum amino acids. Therefore, amino acids were separated by chromatography and incorporation of ${ }^{13} \mathrm{C}$ at specific carbon positions was identified by NMR spectroscopy. The labeling patterns from all three cultures were exactly identical. In addition, genes involved in the de novo biosynthesis of amino acids are missing in the Nanoarchaeum genome. Based on this combined evidence, it was concluded that amino acids are transferred from the I. hospitalis host to the N. equitans cells (Jahn et al., 2008). In addition, cellular macromolecules seem to be exchanged between the partners in the archaeal consortia. In the latter, LC-MS analyses of membrane lipids in their intact polar forms showed very similar chemical patterns in both organisms with archaeol and caldarchaeol constituting the main core lipids. Furthermore, stable isotope labeling $\left({ }^{13} \mathrm{C}\right)$ yielded nearly identical results for the hydrocarbons derived from $N$. equitans and I. hospitalis. Those results, combined with a lack of genes for lipid biosynthesis in the genome of $N$. equitans led to the conclusion that lipids in the archaeal consortium are synthesized in I. hospitalis and transported to its partner organism (Jahn et al., 2004).

Amino acids also seem to be of central importance for other symbioses. The deep sea tube worm Riftia pachyptila is dependent on arginine supplied by its bacterial endosymbionts (Minic and Hervé, 2003), whereas in legume-root nodules, amino acids are used as both an ammonium and a carbon shuttle (Lodwig et al., 2003). Interestingly, Rhizobia become symbiotic auxotrophs for branched chain amino acids after infecting the host plant due to a downregulation of the respective biosynthetic 
pathways, making them dependent on the supply by the plant (Prell et al., 2009).

\section{MECHANISMS OF METABOLITE EXCHANGE}

The very structure of the phototrophic consortium in itself facilitates the putative transfer of compounds from one partner to the other since the direct cell-cell contact prevents a diffusion of compounds over larger distance and hence minimizes transfer time. Theoretically, the metabolic coupling of the two partners of the consortium "C. aggregatum" may be based on an unspecific excretion of substrates by the epibiont followed by the uptake via the central bacterium, or involve specific molecular structures and mechanisms of substrate exchange. Several observations indicate that the latter is the case in "C. aggregatum."

The ultrastructure of the contact sites in "C. aggregatum" and in the archaeal consortia have been studied in detail using different electron microscopy approaches (Junglas et al., 2008; Wanner et al., 2008). In free-living epibionts, as well as in all other known green sulfur bacteria, chlorosomes are distributed evenly among the inner face of the cytoplasmic membrane. However, in the associated state, chlorosomes are absent in the green sulfur bacterial epibionts at the site of attachment to the central bacterium. Replacing the antenna structures, a $17 \mathrm{~nm}$ thick layered structure of yet unknown function has been discovered (Vogl et al., 2006; Wanner et al., 2008). Interestingly, treatment of the epibionts with the extracellular cross-linkers DTSSP and $\mathrm{BS}_{3}$ revealed the branched chain amino acid ABCtransporter binding protein (compare The Regulatory Response Evoked by Symbiosis Involves Genes of the Nitrogen Metabolism) to be cross-linking with other proteins, indicating that it is localized at the cell surface or in the periplasm (Wenter et al., 2010).

In contrast to the epibionts of the phototrophic consortium "Chlorochromatium aggregatum" that maintain a permanent cellcell contact to the central bacterium, Nanoarchaeum equitans has been observed in different states of attachment to Ignicoccus hospitalis. The surface structures of the two organisms may either be in direct contact or, alternatively, in close vicinity to each other. In the latter case, fibers bridging the gap between the cells are clearly visible. In " $C$. aggregatum," connections between the two partner bacteria stretching out from the central bacterium are more prominent than in the archaeal consortium. Periplasmic tubules (PT) are formed by the outer membrane and are in linear contact with the epibionts (Figure 3A). The PT are distributed over the entire cell surface (Figure 3B) and reach $200 \mathrm{~nm}$ in length at the poles of the central bacterium.

It had been speculated that the periplasmic tubules represent connections of a shared periplasmic space (Wanner et al., 2008). However, this could not be confirmed by fluorescence recovery after photobleaching (FRAP)-analyses (Johannes Müller and Jörg Overmann, unpublished observations). After staining of the consortia with calcein acetoxymethylester (calcein AM), only the epibionts but not the central bacterium could be detected by fluorescence microscopy (Figure 4A). Obviously, the central bacterium (arrows in Figure 4A) is lacking an esterase specific for cleaving calcein AM. This result in itself already contradicts the hypothesis of a combined periplasm because the highly fluorescent dye calcein should have diffused after its formation from the epibiont cells into the central bacterium. Furthermore, after subsequent bleaching of one of the epibiont cells (arrowheads in Figures 4B,C) using confocal microscopy, a recovery of fluorescence could not be detected in the bleached cell, which excludes the possibility of free diffusion between the epibiont cells through the interconnecting pili (Figures 4B,C).

A similar experiment has been conducted with the filamentous cyanobacterium Anabaena cylindrica which is considered to be a truly multicellular prokaryote. Single calcein stained cells within an Anabaena filament fully recovered calcein fluorescence $12 \mathrm{~s}$ after bleaching. This effect was ascribed to intercellular channels allowing free diffusion of molecules from cytoplasm to cytoplasm (Mullineaux et al., 2008). Such a rather unspecific transfer is unlikely to occur across the contact site of the phototrophic consortium "C. aggregatum" where it must be much more substrate-specific.

\section{CONCLUSIONS}

While the different types of symbioses and syntrophic associations discussed in the preceding sections all provide an energetic advantage to one or both partners, only few of these associations reached the level of organizational complexity of the highly structured, permanent consortia. Thus, a permanent cell-cell contact is not mandatory in the case of syntrophic cultures in which depletion of substrates can lead to disaggregation of the associations (Peduzzi et al., 2003). The highly developed and obligate interaction in phototrophic consortia is likely to be related to the pronounced energy limitation in the low-light habitats and to the efficient and regulated exchange of metabolites. Phototrophic

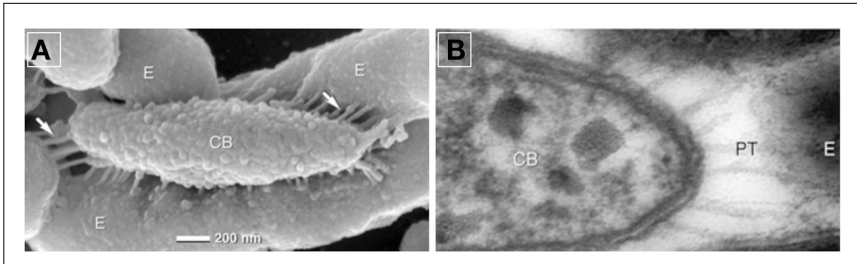

FIGURE 3 | (A) Scanning electron photomicrographs of a partially disaggregated consortium, E, epibiont, $C B$, central bacterium, arrows pointing toward periplasmic tubules (PT). (B) Transmission electron photomicrographs of ultra-thin sections showing elongated PT at the tip of the central bacterium. Modified after Wanner et al. (2008).
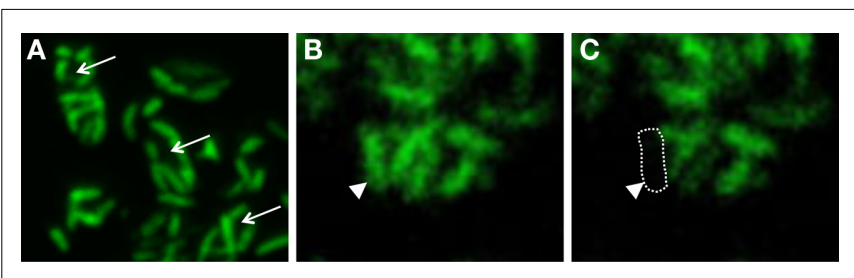

FIGURE 4 | "Chlorochromatium aggregatum" consortia after calcein AM staining. (A) Arrows pointing toward unstained central bacteria. (B,C) Consortium before and after photo-bleaching; arrows pointing toward bleached epibiont cell. 
consortia harboring other prokaryotes than green sulfur bacteria have not been found so far, emphasizing the role of preadaptation of the green sulfur bacterial partner for the development of the symbiosis that was augmented by the gain of specific functions such as genes similar to virulence genes, periplasmic tubules for cell-cell contact or the intracellular sorting of chlorosomes in the epibionts. The gain of motility by the epibiont seems to constitute a selective advantage that led to the coevolution with a motile betaproteobacterium. The recent completion of the central bacterial genome sequence for "C. aggregatum" should help to determine whether and which additional preadaptations of the betaproteobacterium were essential for establishing this symbiosis.

\section{ACKNOWLEDGMENTS}

We thank Anne Bayer for supplying material for Figures $\mathbf{1}$ and $\mathbf{2}$ and Andreas Binder, Genetics, Department Biology I, University of Munich, for help with confocal laser scanning microscopy. This work was supported by a grant of the Deutsche Forschungsgemeinschaft to Jörg Overmann (grant DFG OV20/10-2).

\section{REFERENCES}

Adams, C. J., Redmond, M. C., and Valentine, D. L. (2006). Pure-culture growth of fermentative bacteria, facilitated by $\mathrm{H}_{2}$ removal: bioenergetics and $\mathrm{H}_{2}$ production. Appl. Environ. Microbiol. 72, 1079-1085.

Amesz, J. (1991)."Green photosynthetic bacteria and heliobacteria," in Variations in Autotrophic Life, eds J. M. Shively and L. L. Barton (London: Academic Press), 99-119.

Andersson, S. G. E., and Kurland, C. G. (1998). Ancient and recent horizontal transfer events: the origins of mitochondria. APMIS Suppl. 106, 5-14.

Azam, F., and Malfatti, F. (2007). Microbial structuring of marine ecosystems. Nat. Rev. Microbiol. 5, 782-791.

Bayer, A. I. (2007). Neue Ansätze zur Analyse der bakteriellen Interaktionen in phototrophen Konsortien. Diploma Thesis, University of Munich 180p.

Behrens, S., Lösekann, T., Pett-Ridge, J., Weber, P. K., Ng, W. O., Stevenson, B. S., Hutcheon, I. D., Relman, D. A., and Spormann, A. M. (2008). Linking microbial phylogeny to metabolic activity at the single-cell level by using enhanced element labelingcatalyzed reporter deposition fluorescence in situ hybridization (ELFISH) and NanoSIMS. Appl. Environ. Microbiol. 74, 3143-3150.

Biebl, H., and Pfennig, N. (1978). Growth yields of green sulfur bacteria in mixed cultures with sulfur and sulfate reducing bacteria. Arch. Microbiol. 117, 9-16.

Blankenship, R. E., Madigan, M. T., and Bauer, C. E. (eds). (1995). Anoxygenic Photosynthetic Bacteria (New York, NY: Springer), 1368.

Blumenberg, M., Seifert, R., Reitner, J., Pape, T., and Michaelis, W. (2004). Membrane lipid patterns typify distinct anaerobic methanotrophic consortia. Proc. Natl. Acad. Sci. U.S.A. 101, 11111-11116.

Briegel, A., Ortega, D. R., Tocheva, E. I., Wuichet, K., Zhuo, L., Songye,
C., Müller, A., Iancu, C. V., Murphy, G. E., Dobro, M. J., Zhulin, I. B., and Jensen, G. J. (2009). Universal architecture of bacterial chemoreceptor arrays. Proc. Natl. Acad. Sci. U.S.A. 106, 17181-17186.

Brochier, C., Gribaldo, S., Zivanovic, Y., Confalonieri, F., and Forterre, P. (2005). Nanoarchaea: representatives of a novel archaeal phylum or a fast-evolving euryarchaeal lineage related to Thermococcales? Genome Biol. 6, R42.

Bryant, M. P. (1979). Microbial methane production-theoretical aspects. J. Anim. Sci. 48, 193-201.

Caldwell, D. E., and Tiedje, J. M. (1975). A morphological study of anaerobic bacteria from the hypolimnia of two Michigan lakes. Can. J. Microbiol. 21, 362-376.

Chollet, R., Vidal, J., and O'Leary, M. H. (1996). Phosphoenolpyruvate carboxylase: a ubiquitous, highly regulated enzyme in plants. Annu. Rev. Plant. Physiol. Plant. Mol. Biol. 47, 273-298.

Clement-Metral, J. D., Gantt, E., and Redlinger, T. (1985). A photosystem II-phycobilisome preparation from the red alga, Porphyridium cruentum: oxygen evolution, ultrastructure, and polypeptide resolution. Arch. Biochem. Biophys. 238, 10-17.

Croome, R. L., and Tyler, P. A. (1984). The microanatomy and ecology of "Chlorochromatium aggregatum" in two meromictic lakes in Tasmania. J. Gen. Microbiol. 130, 2717-2723.

Czeczuga, B., and Gradzki, F. (1973). Relationship between extracellular and cellular production in the sulphuric green bactreium Chlorobium limicola Nads. (Chlorobacteriaceae) as compared to primary production of phytoplankton. Hydrobiologia 42, 85-95.

Dubinina, G. A., and Kuznetsov, S. I. (1976). The ecological and morphological characteristica of microorganisms in Lesnaya Lamba (Karelia). Int. Rev. Hydrobiol. 61, 1-19.

Dufresne, A., Garczarek, L., and Partensky, F. (2005). Accelerated evolution associated with genome reduction in a free-living prokaryote. Genome Biol. 6, R14.

Dykhuizen, D. E. (1998). Santa Rosalia revisited: Why are there so many species of bacteria? Antonie van Leeuwenhoek. Int. J. Gen. Mol. Microbiol. 73, 25-33.

Fægri, A., Torsvik, V. L., and GoksÖyr, J. (1977). Bacterial and fungal activities in soil: separation of bacteria and fungi by a rapid fractionated centrifugation technique. Soil Biol. Biochem. 9, 105-112.

Fröstl, J. M., and Overmann, J. (1998). Physiology and tactic response of the phototrophic consortium "Chlorochromatium aggregatum." Arch. Microbiol. 169, 129-135.

Fröstl, J. M., and Overmann, J. (2000). Phylogenetic affiliation of the bacteria that constitute phototrophic consortia. Arch. Microbiol. 174, 50-58.

Ganapathy, S., Oostergetel, G. T., Wawrzyniak, P. K., Reus, M., Gomez Maqueo Chew, A., Buda, F., Boekema, E. J., Bryant, D. A., Holzwarth, A. R., and de Groot, H. J. (2009). Alternating syn-anti bacteriochlorophylls form concentric helical nanotubes in chlorosomes. Proc. Nat. Acad. Sci. U.S.A. 106, 8525-8530.

Gans, J., Wolinsky, M., and Dunbar, J. (2005). Microbiology: computational improvements reveal great bacterial diversity and high toxicity in soil. Science 309, 1387-1390.

Giovannoni, S. J., Tripp, H. J., Givan, S., Podar, M., Vergin, K. L., Baptista, D., Bibbs, L., Eads, J., Richardson, T. H., Noordewier, M., Rappé, M. S., Short, J. M., Carrington, J. C., and Mathur, E. J. (2005). Genetics: genome streamlining in a cosmopolitan oceanic bacterium. Science 309, 1242-1245.

Glaeser, J., Baneras, L., Rütters, H., and Overmann, J. (2002). Novel bacteriochlorophyll $e$ structures and species-specific variability of pigment composition in green sulfur bacteria. Arch. Microbiol. 177, 475-485.
Glaeser, J., and Overmann, J. (2003a). Characterization and in situ carbon metabolism of phototrophic consortia. Appl. Environ. Microbiol. 69, 3739-3750.

Glaeser, J., and Overmann, J. (2003b). The significance of organic carbon compounds for in situ metabolism and chemotaxis of phototrophic consortia. Environ. Microbiol. 5, 1053-1063.

Glaeser, J., and Overmann, J. (2004). Biogeography, evolution, and diversity of epibionts in phototrophic consortia. Appl. Environ. Microbiol. 70, 4821-4830.

Gorlenko, W. M., and Kusnezow, S. I. (1972). Über die photosynthetisierenden bakterien des kononjer-sees. Arch. Hydrobiol. 70, $1-13$.

Griebenow, K., and Holzwarth, A. R. (1989). Pigment organization and energy transfer in green bacteria 1. Isolation of native chlorosomes free of bound bacteriochlorophyll $a$ from Chloroflexus aurantiacus by gel-electrophoretic filtration. Biochim. Biophys. Acta 973, 235-240.

Huber, H., Hohn, M. J., Stetter, K. O., and Rachel, R. (2003). The phylum Nanoarchaeota: present knowledge and future perspectives of a unique form of life. Res. Microbiol. 154, 165-171.

Iino, T., Mori, K., Uchino, Y., Nakagawa, T., Harayama, S., and Suzuki, K. I. (2010). Ignavibacterium album gen. nov., sp. nov., a moderately thermophilic anaerobic bacterium isolated from microbial mats at a terrestrial hot spring and proposal of Ignavibacteria classis nov., for a novel lineage at the periphery of green sulfur bacteria. Int. J. Sys. Evol. Microbiol. 60, 1376-1382.

Ishii, S., Kosaka, T., Hori, K., Hotta, Y., and Watanabe, K. (2005). Coaggregation facilitates interspecies hydrogen transfer between Pelotomaculum thermopropionicum and Methanothermobacter thermautotrophicus. Appl. Environ. Microbiol. 71, 7838-7845. 
Jagmann, N., Brachvogel, H. P., and Philipp, B. (2010). Parasitic growth of Pseudomonas aeruginosa in coculture with the chitinolytic bacterium Aeromonas hydrophila. Environ. Microbiol. 12, 1787-1802.

Jahn, U., Gallenberger, M., Paper, W., Junglas, B., Eisenreich, W., Stetter, K. O., Rachel, R., and Huber, H. (2008). Nanoarchaeum equitans and Ignicoccus hospitalis: new insights into a unique, intimate association of two archaea. J. Bacteriol. 190, 1743-1750.

Jahn, U., Summons, R., Sturt, H., Grosjean, E., and Huber, H. (2004). Composition of the lipids of Nanoarchaeum equitans and their origin from its host Ignicoccus sp. strain KIN4/I. Arch. Microbiol. 182, 404413.

Junglas, B., Briegel, A., Burghardt, T., Walther, P., Wirth, R., Huber, H., and Rachel, R. (2008). Ignicoccus hospitalis and Nanoarchaeum equitans: ultrastructure, cell-cell interaction, and $3 \mathrm{D}$ reconstruction from serial sections of freeze-substituted cells and by electron cryotomography. Arch. Microbiol. 190, 395-408.

Kanzler, B. E. M., Pfannes, K. R., Vogl, K., and Overmann, J. (2005). Molecular characterization of the nonphotosynthetic partner bacterium in the consortium "Chlorochromatium aggregatum." Appl. Environ. Microbiol. 71, 7434-7441.

Krembs, C., Juhl, A. R., Long, R. A., and Azam, F. (1998). Nanoscale patchiness of bacteria in lake water studied with the spatial information preservation method. Limnol. Oceanogr. $43,307-314$

Lauterborn, R. (1906). Zur Kenntnis der sapropelischen flora. Allg. Bot. Z. 12, 196-197.

Lodwig, E. M., Hosie, A. H. F., Bourdès, A., Findlay, K., Allaway, D., Karunakaran, R., Downie, J. A., and Poole, P. S. (2003). Aminoacid cycling drives nitrogen fixation in the legume-Rhizobium symbiosis. Nature 422, 722-726.

Marschall, E., Jogler, M., Henssge, U., and Overmann, J. (2010). Largescale distribution and activity patterns of an extremely low-lightadapted population of green sulfur bacteria in the Black Sea. Environ. Microbiol. 12, 1348-1362.

McInerney, M. J. (1986). Transient and persistent associations among prokaryotes. Bacteria Nat. 2, 293-338.

Melkozernov, A. N., Barber, J., and Blankenship, R. E. (2006). Light harvesting in photosystem I supercomplexes. Biochemistry 45, 331-345.
Minic, Z., and Hervé, G. (2003). Arginine metabolism in the deep sea tube worm Riftia pachyptila and its bacterial endosymbiont. J. Biol. Chem. 278, 40527-40533.

Mira, A., Ochman, H., and Moran, N. A. (2001). Deletional bias and the evolution of bacterial genomes. Trends Genet. 17, 589-596.

Montano, G. A., Bowen, B. P., LaBelle, J. T., Woodbury, N. W., Pizziconi, V. B., and Blankenship, R. E. (2003). Characterization of Chlorobium tepidum chlorosomes: a calculation of bacteriochlorophyll $c$ per chlorosome and oligomer modeling. Biophys. J. 85, 2560-2565.

Moran, N. A., McCutcheon, J. P., and Nakabachi, A. (2008). Genomics and evolution of heritable bacterial symbionts. Annu. Rev. Genet. 42, 165-190.

Moran, P. J., Cheng, Y., Cassell, J. L., and Thompson, G. A. (2002). Gene expression profiling of Arabidopsis thaliana in compatible plant-aphid interactions. Arch. Insect Biochem. Physiol. 51, 182-203.

Müller, N., Griffin, B. M., Stingl, U., and Schink, B. (2008). Dominant sugar utilizers in sediment of Lake Constance depend on syntrophic cooperation with methanogenic partner organisms. Environ. Microbiol. 10, 1501-1511.

Mullineaux, C. W., Mariscal, V., Nenninger, A., Khanum, H., Herrero, A., Flores, E., and Adams, D. G. (2008). Mechanism of intercellular molecular exchange in heterocystforming cyanobacteria. $E M B O \mathrm{~J} .27$, 1299-1308.

Orphan, V. J., House, C. H., Hinrichs, K. U., McKeegan, K. D., and DeLong, E. F. (2001). Methane-consuming archaea revealed by directly coupled isotopic and phylogenetic analysis. Science 293, 484-487.

Overmann, J. (2001a). "Green sulfur bacteria," in Bergey's Manual of Systematic Bacteriology, 2nd Edn. Vol. 1, eds D. R. Boone and R. W. Castenholz (Baltimore: Williams and Wilkins), 601-630.

Overmann, J. (2001b)."Phototrophic consortia: a tight cooperation between non-related eubacteria," in Symbiosis: Mechanisms and Model Systems, ed. J. Seckbach (Dordrecht: Kluwer Academic Publishers), 239-255.

Overmann, J., Cypionka, H., and Pfennig, N. (1992). An extremely lowlight-adapted phototrophic sulfur bacterium from the Black Sea. Limnol. Oceanogr. 37, 150-155.

Overmann, J., Lehmann, S., and Pfenning, N. (1991). Gas vesicle formation and buoyancy regulation in Pelodictyon phaeoclathratiforme (Green sulfur bacteria). Arch. Microbiol. 157, 29-37.

Overmann, J., and Schubert, K. (2002). Phototrophic consortia: model systems for symbiotic interrelations between prokaryotes. Arch. Microbiol. 177, 201-208.

Overmann, J., Tuschak, C., Sass, H., and Fröstl, J. (1998). The ecological niche of the consortium "Pelochromatium roseum." Arch. Microbiol. $169,120-128$

Paerl, H. W., and Kellar, P. E. (1978). Significance of bacterial (Cyanophyceae) Anabaena associations with respect to $\mathrm{N}_{2}$ fixation in freshwater. J. Phycol. 14, 254-260.

Peduzzi, S., Tonolla, M., and Hahn, D. (2003). Isolation and characterization of aggregate-forming sulfatereducing and purple sulfur bacteria from the chemocline of meromictic Lake Cadagno, Switzerland. FEMS Microbiol. Ecol. 45, 29-37.

Perfiliev, B. V. (1914). On the theory of symbiosis of 'Chlorochromatium aggregatum' Lauterb. (Chloronium mirabile Buder) and Cylindrogloea bacterifera nov. gen., nov. spec. (in Russian). Mikrobiol. Petrogr. 1, 222-225.

Perna, N. T., Plunkett, G., Burland, V., Mau, B., Glasner, J. D., Rose, D. J., Mayhew, G. F., Evans, P. S., Gregor, J., Kirkpatrick, H. A., Pósfai, G., Hackett, J., Klink, S., Boutin, A. Shao, Y., Miller, L., Grotbeck, E. J., Davis, N. W., Lim, A., Dimalanta, E. T., Potamousis, K. D., Apodaca, J., Anantharaman, T. S., Lin, J., Yen, G., Schwartz, D. C., Welch, R. A., and Blattner, F. R. (2001). Genome sequence of enterohaemorrhagic Escherichia coli O157:H7. Nature 409, 529-533.

Pernthaler, A., Dekas, A. E., Brown, C. T., Goffredi, S. K., Embaye, T., and Orphan, V. J. (2008). Diverse syntrophic partnerships from deep-sea methane vents revealed by direct cell capture and metagenomics. Proc. Natl. Acad. Sci. U.S.A. 105 , 7052-7057.

Pfannes, K. R. (2007). Characterization of the Symbiotic Bacterial Partners in Phototrophic Consortia. Dissertation, University of Munich, 180p.

Pfannes, K. R., Vogl, K., and Overmann, J. (2007). Heterotrophic symbionts of phototrophic consortia: members of a novel diverse cluster of Betaproteobacteria characterized by a tandem rrn operon structure. Environ. Microbiol. 9, 2782-2794.

Pfennig, N. (1978). "General physiology and ecology of photosynthetic bacteria", in The Photosynthetic Bacteria, eds R. K. Clayton and W. R.Sistrom (New York, NY: Plenum Press), 3-18.

Pfennig, N. (1980). "Syntrophic mixed cultures and symbiotic consortia with phototrophic bacteria: a review," in Anaerobes and Anaerobic Infections, eds G. Gottschalk and P. N. Werner (Stuttgart, NY: Fischer), 127-131.

Podar, M., Anderson, I., Makarova, K. S., Elkins, J. G., Ivanova, N., Wall, M. A., Lykidis, A., Mavromatis, K., Sun, H., Hudson, M. E., Chen, W., Deciu, C., Hutchison, D., Eads, J. R., Anderson, A., Fernandes, F., Szeto, E., Lapidus, A., Kyrpides, N. C., Saier, M. H., Richardson, P. M., Rachel, R., Huber, H., Eisen, J. A., Koonin, E. V., Keller, M., and Stetter, K. O. (2008). A genomic analysis of the archaeal system Ignicoccus hospitalis-Nanoarchaeum equitans. Genome Biol. 9, R158.

Prell, J., White, J. P., Bourdes, A., Bunnewell, S., Bongaerts, R. J., and Poole, P. S. (2009). Legumes regulate Rhizobium bacteroid development and persistence by the supply of branched-chain amino acids. Proc. Natl. Acad. Sci. U.S.A. 106, 12477-12482.

Reva, O., and Tümmler, B. (2008). Think big - Giant genes in bacteria. Environ. Microbiol. 10, 768-777.

Schink, B. (1992). "Syntrophism among prokaryotes," in The Prokaryotes, 2nd edn. eds A. Balows, H. G. Trüper, M. Dworkin, W. Harder, and K.-H. Schleifer (New York, NY: Springer Verlag), 276-299.

Sirevag, R., and Ormerod, J. G. (1970). Carbon dioxide fixation in green sulphur bacteria. Biochem. J. 120, 399-408.

Skuja, H. (1956). Taxonomische und biologische Studien über das Phytoplankton schwedischer Binnengewässer. Nova. Acta. Reg. Soc. Sci. Upsal. Ser 4 16, 1-404.

Trüper, H. G., and Pfennig, N. (1971). Family of phototrophic green sulfur bacteria: Chlorobiaceae Copeland, the correct family name; rejection of Chlorobacterium Lauterborn; and the taxonomic situation of the consortium-forming species. Int. J. Syst. Bacteriol. 21, 8-10.

Tuschak, C., Glaeser, J., and Overmann, J. (1999). Specific detection of green sulfur bacteria by in situ hybridization with a fluorescently labeled oligonucleotide probe. Arch. Microbiol. 171, 265-272.

Uyeda, K., and Rabinowitz, J. C. (1971). Pyruvate-ferredoxin oxidoreductase. IV. Studies on the reaction mechanism. J. Biol. Chem. 246, 3120-3125. 
Van Grondelle, R., Hunter, C. N., Bakker, J. G. C., and Kramer, H. J. M. (1983). Size and structure of antenna complexes of photosynthetic bacteria as studied by singlet-singlet quenching of the bacteriochlorophyll fluorescence yield. Biochim. Biophys. Acta. 723, 30-36.

Veldhuis, M. J. W., and van Gemerden, H. (1986). Competition between purple and brown phototrophic bacteria in stratified lakes: sulfide, acetate, and light as limiting factors. FEMS Microbiol. Lett. 38, 31-38.

Vogl, K., Glaeser, J., Pfannes, K. R., Wanner, G., and Overmann, J. (2006). Chlorobium chlorochromatii sp. nov., a symbiotic green sulfur bacterium isolated from the phototrophic consortium "Chlorochromatium aggregatum.” Arch. Microbiol. 185, 363-372.

Vogl, K., Wenter, R., Dressen, M., Schlickenrieder, M., Ploscher, M., Eichacker, L., and Overmann, J. (2008). Identification and analysis of four candidate symbiosis genes from 'Chlorochromatium aggregatum', a highly developed bacterial symbiosis. Environ. Microbiol. 10, 2842-2856.

Wanner, G., Vogl, K., and Overmann, J. (2008). Ultrastructural characterization of the prokaryotic symbiosis in "Chlorochromatium aggregatum." J. Bacteriol. 190, 3721-3730.

Warthmann, R., Cypionka, H., and Pfennig, N. (1992). Photoproduction of $\mathrm{H}_{2}$ from acetate by syntrophic cocultures of green sulfur bacteria and sulfur-reducing bacteria. Arch. Microbiol. 157, 343-348.

Waters, E., Hohn, M. J., Ahel, I., Graham, D. E., Adams, M. D., Barnstead, M., Beeson, K. Y., Bibbs, L., Bolanos, R., Keller, M., Kretz, K., Lin, X., Mathur, E., Ni, J., Podar, M., Richardson, T., Sutton, G. G., Simon, M., Soll, D., Stetter, K. O., Short, J. M., and Noordewier, M. (2003). The genome of Nanoarchaeum equitans: insights into early archaeal evolution and derived parasitism. Proc. Natl. Acad. Sci. U.S.A. 100, 12984-12988.

Wenter, R., Hütz, K., Dibbern, D., Li, T., Reisinger, V., Ploscher, M., Eichacker, L., Eddie, B., Hanson, T., Bryant, D. A., and Overmann, J. (2010). Expression-based identification of genetic determinants of the bacterial symbiosis 'Chlorochromatium aggregatum'. Environ. Microbiol. 12, 2259-2276.

Whitman, W. B., Coleman, D. C., and Wiebe, W. J. (1998). Prokaryotes: the unseen majority. Proc. Natl. Acad. Sci. U.S.A. 95, 6578-6583.

Zehnder, A. J. B., Ingvorsen, K., and Marti, T. (1982). "Microbiology of methane bacteria," in Anaerobic Digestion, eds D. E. Hughes, D. A. Stafford, B. I. Wheatley, W. Baader, G. Lettinga, E. J. Nyns, W. Verstraete, and R. L. Wentworth (Amsterdam: Elsevier Biomedical Press), 45-68.

Conflict of Interest Statement: The authors declare that the research was conducted in the absence of any commercial or financial relationships that could be construed as a potential conflict of interest.

Received: 24 February 2011; paper pending published: 26 April 2011; accepted: 20 June 2011; published online: 05 July 2011. Citation: Müller J and Overmann J (2011) Close interspecies interactions between prokaryotes from sulfureous environments. Front. Microbio. 2:146. doi: 10.3389/fmicb.2011.00146

This article was submitted to Frontiers in Microbial Physiology and Metabolism, a specialty of Frontiers in Microbiology. Copyright (c) 2011 Müller and Overmann. This is an open-access article subject to an exclusive license agreement between the authors and the Articles Research Foundation, which permits unrestricted use, distribution, and reproduction in any medium, provided the original authors and source are credited. 